\title{
Jornalismo adversário: a crise do segundo mandato de Dilma Rousseff na capa do jornal Li-Chang Shuen
}

Universidade Federal do Maranhão, São Luís, Maranhão, Brasil

\section{Resumo}

$\mathrm{O}$ artigo analisa a narrativa do jornalismo adversário nas manchetes e chamadas de capa dos jornais O Globo e Folha de S. Paulo durante a crise do segundo mandato da presidente Dilma Rousseff. Trabalhamos com o conceito de jornalismo adversário e com a noção de imprensa como partido político para explicar o papel dos jornais na crise que culminou com o impeachment da presidente eleita. Utilizamos a análise crítica da narrativa para analisar as 793 unidades textuais que compõem o corpus da pesquisa. Os resultados mostram que os jornais comportaram-se como contendores políticos e foram agentes ativos no processo de desestabilização do governo durante a crise.

\section{Palavras-Chave}

Jornalismo Adversário. Narrativa. Dilma Rousseff.

\section{Introdução}

Brasília, quinta-feira, 12 de maio de 2016. Os 81 senadores da República reuniam-se em plenário para decidir se o processo de impeachment da presidente Dilma Rousseff, autorizado previamente pela Câmara dos Deputados com o aval de 367 deles, seria acatado por esta segunda casa, afastando provisoriamente a governante de suas funções e dando posse ao vice-presidente Michel Temer. Com 55 votos pelo "sim", o Senado afastou temporariamente Dilma de seu cargo, decisão que seria ratificada em agosto. $\mathrm{O}$ mandato $\mathrm{da}$ presidente eleita acabou, efetivamente, em 12 de maio (apesar de, formalmente, ele ter se estendido até a decisão definitiva do Senado, em 10 de agosto). Entre a reeleição e o afastamento de Dilma, uma crise política e econômica monopolizou as capas dos principais jornais do país, que narraram a inviabilidade do segundo mandato de Dilma, narrativa esta que é objeto de análise neste artigo.

É importante deixar claro que nosso objeto de análise não é a história concreta, mas a versão 
que o jornalismo construiu dessa história. Nosso objetivo, portanto, não é reconstruir o processo político do impeachment, mas analisar a narrativa midiática que deu sustentação à atuação da imprensa como adversário do governo reeleito. Dito de maneira mais simples, nosso objetivo é analisar a forma como o jornalismo adversário manifestou-se concretamente nas páginas dos jornais durante a crise do segundo mandato de uma presidente que já sofria, em sua primeira investidura, com a oposição da imprensa.

A pesquisa contemplou manchetes e chamadas de capa de dois jornais: Folha de S. Paulo e O Globo, escolhidos por serem os dois jornais de maior circulação nacional, representativos de dois centros importantes da política e da economia brasileiras: São Paulo e Rio de Janeiro. São, portanto, os porta-vozes das elites desses dois estados, elites estas que detêm importante parcela de poder e influência sobre o restante do país, uma vez que dialogam com os mesmos interesses.

A hipótese de trabalho é que os jornais, como instituição e atores políticos, contribuíram com a sua narrativa para desestabilizar o governo ao amplificarem a crise. A realidade política é complexa demais, e os atores envolvidos, os mais variados, com interesses igualmente variados. Mas, justamente porque convergiram, esses interesses e atores encontraram nas páginas dos jornais o local de diálogo entre eles e de enfrentamento ao governo. O jornalismo adversário foi um elemento de desestabilização, que se somou a outros - que não serão contemplados nesta pesquisa.

O artigo, além desta introdução e das considerações finais, apresenta uma descrição da metodologia utilizada, uma discussão teórica sobre o jornalismo adversário e a análise da narrativa encontrada nos dois jornais estudados sobre a crise do segundo mandato de Dilma Rousseff. Apresentamos gráficos com os dados quantitativos que dão suporte à análise qualitativa, pois acreditamos que a complexidade de uma cobertura jornalística pode ser melhor apreendida quando dados quantitativos e qualitativos se complementam, reduzindo a subjetividade, que não é característica apenas do jornalismo, mas também da pesquisa que tem o jornalismo como objeto.

\section{Notas metodológicas}

Durante o período de coleta da pesquisa, entre 27 de outubro de 2014 e 13 de maio de 2016 , foram catalogadas 5.698 manchetes e chamadas sobre Dilma e seu governo, publicadas nos jornais Folha de S. Paulo, O Globo, Estado de Minas e Valor Econômico. Para o corpus final de análise foram consideradas apenas as manchetes e chamadas de capa divulgadas pelos jornais Folha 
de S. Paulo e O Globo. A opção por esses tipos textuais justifica-se porque acreditamos que manchetes e chamadas estampadas nas capas dos jornais oferecem uma boa amostra da política editorial de qualquer veículo impresso. Afinal, é a partir da capa que os jornais seduzem seus leitores e, por ser a parte mais visível, a capa pode ser lida por qualquer pessoa: desde a que assina ou a que adquire um exemplar avulso em banca até aquela que apenas passa os olhos na edição enquanto observa a oferta nas bancas, em consultórios e outros locais em que os diários ficam expostos. Optamos, assim, por também não incluir o lead que acompanha as manchetes e chamadas. Utilizamos apenas os títulos.

A composição do corpus é esta: jornais Folha de S. Paulo e O Globo, escolhidos pelo critério circulação; apenas manchetes e chamadas; apenas manchetes e chamadas com valência (viés) negativa; apenas manchetes que citam Dilma ou Presidente/a ou Governo/Planalto ou Petista (para se referir à Dilma) no título; apenas os títulos das manchetes e chamadas. Com esse recorte, processamos um total de 793 unidades textuais. O período de composição do corpus foi de 27 de outubro de 2014 (dia seguinte à reeleição) a 13 de maio, dia seguinte à abertura do processo de impeachment no Senado. Consideramos, portanto, que o segundo mandato de Dilma começou em 27 de outubro de 2014 e encerrou-se em 12 de maio de 2016. Ao todo são 359 manchetes e chamadas da Folha e 434 de O Globo.

A análise da narrativa jornalística obedeceu aos seguintes passos: identificação da intriga; identificação dos personagens; identificação do narrador/das vozes que contam a história; reconstrução da intriga; análise. Na narração jornalística, o primeiro narrador é sempre o veículo, que subordina o narrador-jornalista que assina as reportagens (há ainda o terceiro-narrador, o personagem de quem se fala). Nesta pesquisa interessa o narrador de primeira instância ou de maior nível hierárquico: os jornais. O estudo das chamadas e manchetes de capa torna essa escolha obrigatória; afinal, esses textos (assim como os editoriais) falam pelo coletivo que denominamos jornal (MOTTA, 2013).

Partimos do pressuposto de que, na narrativa da crise do segundo mandato de Dilma, o primeiro narrador toma parte na história como instituição política oposicionista. Definidos os critérios de seleção da amostra, a pesquisa atravessou duas fases para a construção do corpus: a primeira, manual, foi a seleção propriamente dita a partir do banco de dados de manchetes e chamadas cadastradas pela equipe do Manchetômetro. O banco de dados reúne as notícias divulgadas diariamente pelos jornais Folha de S. Paulo, 
O Globo, O Estado de Minas, Estadão, Valor Econômico e pelo telejornal Jornal Nacional. Nesse banco de dados, para o nosso recorte temporal, há 29.710 notícias cadastradas tanto sobre o governo Dilma quanto sobre outros personagens recorrentes no noticiário nesse período (Lula, FHC, Geraldo Alckmin, Aécio Neves, Eduardo Cunha, Michel Temer etc.).

Durante o período recortado, e envolvendo os vários personagens da crise do segundo mandato de Dilma, a Folha de S. Paulo publicou 599 manchetes e 2. 591 chamadas de capa. Já o jornal O Globo publicou 615 manchetes e 3.066 chamadas de capa. O volume de informação disponível requereu o estabelecimento dos critérios já citados. A seleção foi feita a partir da leitura individual das notícias cadastradas dos dois jornais escolhidos para a pesquisa.

A segunda fase de construção do corpus diz respeito ao tratamento dos textos. Utilizamos o programa de análise textual Iramuteq, um software livre que oferece análises estatísticas e gráficos da análise linguística feita a partir da amostra. Para que o programa faça corretamente a análise, o pesquisador precisa digitar a amostra textual no Open Office ou similar, criando linhas de comando para cada unidade textual. Devem ser criadas linhas para cada um dos textos. Em cada linha, o pesquisador deve codificar o número do texto daquela amostra, o tipo de texto e quaisquer informações relevantes para a sua análise; na linha abaixo, deve digitar o texto. Nesta pesquisa, as linhas-padrão foram assim definidas: ${ }^{* * * * * * *}$ N_OOI ${ }^{*}$ TEM_2 *TIP_I (N_refere-se ao número do texto na amostra; TEM_refere-se à editoria, sendo 1 para Política e 2 para Economia; e TIP_refere-se ao tipo do texto, sendo 1 para manchetes e 2 para chamadas). Para cada jornal foi aberto um arquivo diferente, obedecendo a esse padrão de codificação. Após o processamento dos arquivos no Iramuteq, partiu-se para a análise qualitativa dos dados quantitativos, tanto aqueles fornecidos pelo software quanto daqueles disponíveis no Manchetômetro.

\section{Não foi um cão de guarda que latiu para Dilma: uma discussão teórica sobre jornalismo cão de guarda e jornalismo adversário no contexto brasileiro}

A narrativa jornalística é um artefato cultural e político. A unidade dessa narrativa, a notícia, é um produto contextual: não depende apenas do fluxo dos acontecimentos, mas também de fatores sociais, econômicos, culturais, políticos, organizacionais e até pessoais (dos jornalistas). O que se diz é tão importante quanto o que não se diz: nos silenciamentos também há discursos. A teoria do jornalismo, de base majoritariamente sociológica, reconhece, ao longo de seu desenvolvimento, que a notícia é um artefato que ajuda a estruturar 
a realidade, em um processo de construção daquilo que as pessoas vão consumir como real e tangível (TRAQUINA, 2004; TUCHMAN, 1983; SOUSA, 2002; ALSINA, 1996).

Os avanços do campo teórico já nos permitem perceber no jornalismo mais que uma atividade que cumpre uma função social: jornalismo, agora, é cada vez mais percebido como ator social e político, cuja atuação vai muito além de reportar o mundo (THOMPSON, 2002; SPARROW, 1999; GRABER, MACQUAIL \& NORRIS, 2008; COOK, 2005; MIGUEL, 2002; LIMA, 2006; ALDÉ, MENDES \& FIGUEIREDO, 2007; FERES JUNIOR, BARBABELA, MIGUEL \& SASSARA, 2015). As manchetes e chamadas de capa são o primeiro contato do público com a notícia: é por meio delas que o jornal capta a atenção do leitor. Sua função, porém, não é apenas o de seduzir, mas principalmente o de estabelecer o pacto de leitura que o consumidor da notícia tem à sua disposição para aderir ou rechaçar.

Enquanto narrativa que atinge públicos massivos, "O jornalismo é a narrativa hegemônica sobre todas as outras na construção da verdade imediata e do senso comum" (моттA, 2013, p. 103). A história imediata (para alguns, história do presente) é, na verdade, uma história mediada pelos textos que são, apenas na superfície, informativos. A notícia, por mais que tenha sido escrita de acordo com a mais estrita técnica de redação jornalística, traz sempre uma intencionalidade, nunca é um discurso neutro ou inocente (FAIRCLOUGH, 1995; VAN DJIK, 1996). A ideia de imparcialidade e objetividade funciona como um véu que mascara o quão político é o jornalismo (COOK, 2005). Concordando com Lattman-Weltman e Chagas (2016, p. 327), não devemos esquecer que

[...] toda possível neutralidade, assim como todo viés, é função do contexto em que se dá não somente a efetividade da informação, mas também quaisquer outras reapropriações da mesma. Daí a natureza intrinsecamente política da instituição (a despeito de sua autonomização como negócio).

Uma visão crítica do jornalismo permite-nos, inclusive, diferenciar duas categorias que podem se confundir: o jornalismo como "cão de guarda" (watchdog journalism) e o jornalismo "adversário" (adversarial journalism). A tradição de ver o jornalismo como cão de guarda, ou seja, como atividade que vigia os poderosos e denuncia seus malfeitos e as mazelas do poder, tem um cunho funcionalista e não aprofunda a discussão sobre as intencionalidades da narrativa jornalística.

A visão de jornalismo como agente de vigilância é um resquício romântico que se mantém, mas o entendimento de que essa vigilância não é desinteressada faz avançar o campo teórico em direção tanto à noção de jornalismo adversário quanto à de jornalismo como instituição 
política. Como forma de buscar credibilidade, autoridade e legitimidade para um veículo de comunicação, o jornalismo adversário

[...] se caracteriza por ter como finalidade principal legitimar o próprio jornalismo como um poder $e$ ator fundamental da cena pública. Tal cobertura baseia-se na oposição entre os campos jornalístico e político, através da desqualificação intensa da política, seus principais atores e instituições representativas (GUAZINA, 2011, p. 19).

A economia simbólica dos meios de comunicação ajuda a explicar a forma como o jornalismo adversário funciona em tempos de crise. Quanto mais alinhados aos interesses dos grupos que estão no poder, mais os jornais tendem ao advocacy journalism; quanto mais distantes desses interesses, mais eles tendem a agir como atores políticos adversários. O embate não é apenas simbólico: nas notícias, flui a disputa pela legitimidade de discursos, de vozes e da própria realidade. Bird e Dardenne (2009), inclusive, pontuam que as notícias, como um processo narrativo, podem funcionar como um mito, que é uma versão da realidade construída para caber nos limites cognitivos de quem não tem autonomia para experienciar a realidade por si mesmo e a experimenta pela mediação dos agentes da indústria da informação.

É nos momentos de crises econômicas e políticas que o jornalismo tem, de maneira mais forte, diante de si a opção pelo jornalismo como cão de guarda, de um lado, ou pelo jornalismo adversário, de outro. Lattman-Weltman, Carneiro e Ramos (1994, p. 8) chamam a atenção para o caso brasileiro:

[...] não se pode deixar de notar que as crises políticas brasileiras, manipuladas e elaboradas no sentido de derrubar poderes estabelecidos, tiveram invariavelmente acoIhida nas redações dos jornais, provocaram sequelas imediatas no Congresso e desembocaram, por fim, nos redutos infalíveis das conspirações castrenses. Em nenhum desses casos a participação da imprensa no desencadeamento de uma ofensiva sistemática, destinada a liquidar situações políticas dominantes, conquistou projeção parcial ou êxitos definitivos, sem o tiro de misericórdia disparado pelos quartéis. 0 único exemplo que se colocou em distonia com os fatos históricos antecedentes, e no qual o movimento em prol da deposição de um presidente foi bem-sucedido sem que para isso fosse preciso romper com os mecanismos constitucionais, foi a queda do governo Collor.

Podemos acrescentar: agora, temos o exemplo do governo Dilma Rousseff, cujo ocaso não dependeu dos quartéis, mas foi bastante influenciado pela atuação da imprensa não apenas como porta-voz de seus adversários, mas ela própria como contendora política ativa em todo o período de crise.

A tradição funcionalista aponta para o jornalismo como vigilante do meio - cão de guarda. 
O modelo liberal de jornalismo adotado inicialmente nos Estados Unidos previa a separação entre fato e opinião e impunha o critério da objetividade como forma de angariar credibilidade ao trabalho da imprensa. Neste modelo, o jornalista é alguém que empresta seus olhos e seus ouvidos ao público, denunciando as mazelas do exercício do poder e garantindo à democracia um serviço de vigilância dos atos dos poderosos.

Em recente estudo, Carolina Matos (2008) afirma que o jornalismo, no Brasil, configurava-se como o que ela chama de jornalismo militante até a redemocratização, quando finalmente o modelo comercial de jornalismo teria instituído o cão de guarda como tipo predominante de jornalismo praticado por nossa imprensa. Waisbord (2000), em obra que analisa a relação entre as notícias e a democracia na América do Sul, usa a expressão "jornalismo cão de guarda" como sinônimo de jornalismo investigativo. Norris e Odugbemi (2010, p. 380) resumem a perspectiva funcionalista do jornalismo, segundo a qual

The watchdog journalism role requires the News media to provide a check on powerful sectors of Society, including leaders within the private and public domains. Journalists are expected to guard the public interest and to protect it from incompetence, corruption and misinformation.

A Nieman Fundation for Journalism, da Universidade de Harvard, mantém o Nieman Watchdog Journalism Projetc. O projeto é um exemplo da visão liberal-funcionalista do jornalismo, que sobrevive, sobretudo no imaginário das redações, apesar dos avanços teóricos no campo. Segundo os teóricos e profissionais associados ao projeto,

The premise of watchdog journalism is that the press is a surrogate for the public, asking probing, penetrating questions at every level, from the town council to the state house to the White House, as well as in corporate and professional offices, in union halls, on university campuses and in religious organizations that seek to influence governmental actions. The goal of watchdog journalism is to see that people in power provide information the public should have ${ }^{1}$.

Uma visão estritamente funcionalista não leva em consideração um aspecto importante para se compreender a notícia em contextos democráticos: a imprensa também é uma instituição política, já que age como ator político e coloca-se a serviço de interesses que ultrapassam o interesse público. Já o jornalista, como empregado em uma empresa capitalista, tem pouca ingerência 
sobre a linha editorial do veículo em que trabalha. No modelo de jornalismo dito liberal, a atuação individual do jornalista não produz efeitos nem de sentido nem de mudança social, pois o agente individual está absorvido pela lógica institucional da imprensa. O jornalista "desaparece" da narrativa impressa nas páginas do jornal - ele é substituído pela voz institucional. Seu nome, assinado nas matérias que produz, individualiza o autor do texto, mas não o agente construtor da narrativa, visto que este é um agente coletivo: o jornal.

Pippa Norris é uma das principais pesquisadoras norte-americanas a desenvolver o conceito de jornalismo como cão de guarda atualmente (ver, em especial, NORRIS 2009; NORRIS E NAI, 2017, cap.10). Em seus textos, a autora defende que o jornalismo tem a responsabilidade de ajudar a guardar o interesse público ao agir como agenda-setter (aquele que tem a responsabilidade de trazer assuntos para discussão na esfera pública) e como gate-keeper (aquele que tem a responsabilidade de refletir os diferentes pontos de vista dentro de uma democracia). Essas funções (vigilante do meio, agenda-setter e gate-keeper) colocam ênfase em um jornalismo como agente político "neutro", no máximo um quarto poder que contrabalanceia os três poderes republicanos, interessado apenas no "bem comum".
Vem da tradição de pesquisa em comunicação política norte-americana o conceito de jornalismo adversário, com ênfase na atuação da imprensa como instituição política. O trabalho de Timothy Cook, Governing with the News: the News media as a political institution (2005) apresenta uma análise sistematizada sobre a relação entre os governos americanos e a imprensa. $\mathrm{O}$ autor demonstra que os presidentes estadunidenses que contavam com o beneplácito dos jornais tinham governos menos turbulentos, e suas medidas tinham maior aceitação popular. Governar com a imprensa era fundamental. Governar contra ela deveria ser evitado a todo custo, e isso explica a institucionalização do departamento de imprensa e relações públicas da Casa Branca. Para este autor, a ideia de objetividade e imparcialidade funciona como um véu que mascara o quão político é o jornalismo. A crítica ao modelo liberal teorizado pelos funcionalistas, ao não levarem em consideração que os jornais não se comunicam com o público, e sim com as elites políticas, leva ao conceito de jornalismo adversário, praticado de acordo com as conveniências da imprensa como ator político.

Bartholomew Sparrow, em seu livro Uncertain Guardians: the News media as a political institution (1999), é um dos cientistas políticos norte-americanos pioneiros na defesa da tese da imprensa como instituição política naquele país. Ele contesta a visão, globalmente 
difundida pelo modelo liberal de jornalismo, de que a imprensa é um quarto poder ou um quarto ramo do governo. Segundo o autor, a imprensa afeta o processo de policy making como qualquer outra instituição política em uma democracia moderna e age independentemente dos interesses governamentais sempre que conveniente. A imprensa pode agir contra os interesses do governo e, em último caso, da própria democracia. É a perspectiva do jornalismo adversário, possível a partir de uma crítica da imprensa como instituição política.

No Brasil, o jornalismo que se pratica tem algumas características de vigilante do meio, mas é predominantemente adversário quando os grupos no poder não estão em sintonia com os grupos que controlam as empresas de comunicação. A imprensa aqui ainda age de forma militante, tanto no nível local como no nacional. É no diálogo com pesquisadores de comunicação política que a perspectiva do jornalismo adversário escapa do viés funcionalista e passa a ser estudado a partir de uma perspectiva crítica. Podemos apontar como exemplos os trabalhos de Guazina (2011), Lattman-Weltman, Carneiro e Ramos (1994), Miguel (2002) e Lima (2006), contribuições que apontam a imprensa como ator político, já que lançam questionamentos sobre a atuação partidarizada da mídia em determinados contextos e eventos.
Nesta pesquisa, privilegiamos a perspectiva do jornalismo adversário em detrimento do jornalismo cão de guarda, pois defendemos que a imprensa é uma instituição política que age de acordo com interesses, próprios ou de grupos a ela alinhados, independente da vontade de governos e governantes. A imprensa tem uma agenda política própria e atua ao lado dos grupos que a sustentam em oposição àqueles que representam ameaças aos seus interesses.

Os jornais são canal de diálogo entre as elites políticas e econômicas que circulam por suas páginas. Embora sejam vendidos em banca e disponibilizados em plataformas online para quem quiser ter acesso ao seu conteúdo, os jornais são veículos que permitem o diálogo entre elites que governam o país, sempre em disputa, sempre em busca de hegemonia. A estrutura da propriedade dos meios de comunicação no Brasil explica esse papel exercido pela imprensa tradicional: grandes conglomerados de mídia pertencem a políticos ou são dirigidos por eles, tanto em nível regional quanto nacional. Os três maiores partidos de oposição ao governo Dilma - DEM, MDB e PSDB - controlam, juntos, 149 empresas de comunicação. Os veículos pertencentes a empresários não parlamentares alinharam sua narrativa à das elites políticas, na medida em que os interesses de uma e de outra convergiam: a desestabilização do governo eleito. 


\section{A crise política do segundo mandato da presidente Dilma Rousseff na Folha de S. Paulo e em 0 Globo}

A reeleição de Dilma, em 26 de outubro de 2014, ensejou a articulação de uma frente política que tomaria corpo nos meses seguintes: oposição derrotada nas urnas e imprensa alinhada com os interesses dessa oposição. A instabilidade política e a prática de jornalismo adversário, que já ocorriam durante o primeiro mandato de Dilma, acentuou-se. Ao iniciar oficialmente o segundo mandato, em 1 de janeiro de 2015 , a presidente não desfrutou do chamado "período de lua de mel" com a imprensa. Nem com o Congresso: a eleição do deputado Eduardo Cunha para a presidência da casa é um dos marcos da crise que culminou com o impeachment da presidente.
A reeleição de Dilma foi noticiada de forma lacônica pelos jornais Folha de S. Paulo e O Globo. Ambos os jornais destacaram nos leads de suas manchetes o fato de que a reeleição foi “apertada”. A Folha foi explícita já em seu título ("Dilma é reeleita na disputa mais apertada da história") a respeito do país que surgiu das urnas: uma nação dividida que teria pela frente um governo em constante escrutínio. Na capa da edição de 27 de outubro de 2014 , ambos os jornais trouxeram notícia na capa (lead + complementos) do cenário que emergiu das urnas, com o enfoque que apontou os rumos na narrativa de cada um desses jornais ao longo do novo mandato conferido a Dilma. O Globo deu destaque para o cenário político ("Seu maior desafio, no quarto mandato consecutivo do PT no poder federal, será unir o país, que se dividiu ao meio nas urnas"), e a Folha, ao cenário

Gráfico 1: Cobertura negativa agregada para o marcador Dilma Rousseff

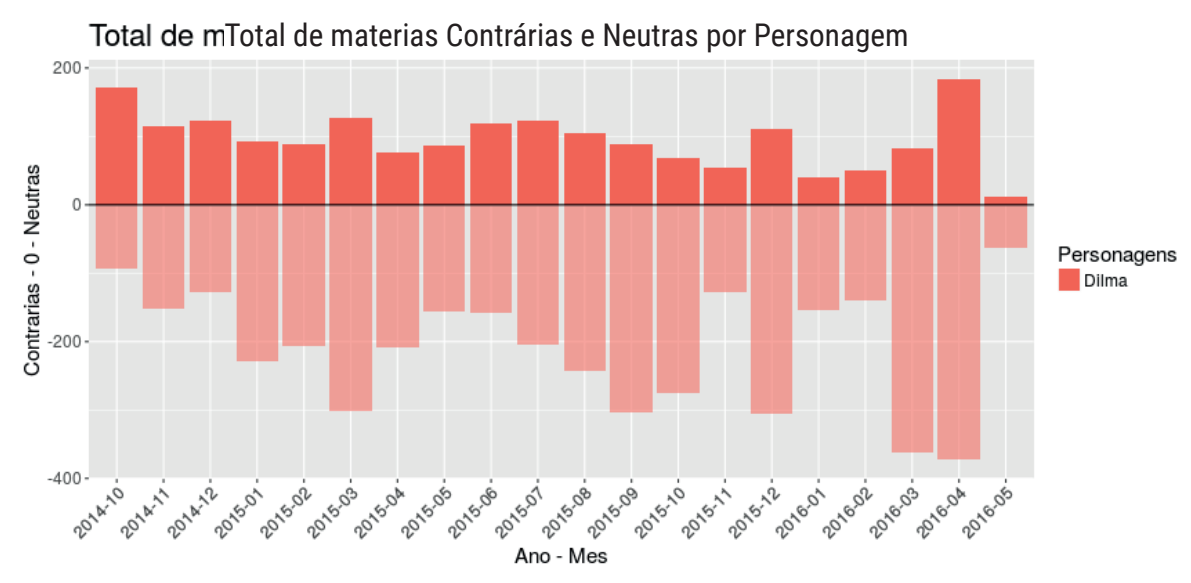

Fonte: Manchetômetro. Gráfico personalizado a partir da cobertura para a personagem Dilma nos jornais Folha de S. Paulo, Estadão, 0 Globo e Jornal Nacional de out/14 a mai/16 
econômico ("No novo governo, a petista terá que lidar com um cenário econômico negativo - de crescimento baixo, inflação em alta e desconfiança dos investidores-e com o escândalo de desvio de recursos da Petrobras").

Ambos os jornais têm a característica de fazer chamada de capa para os textos de opinião que publicam em páginas internas. No dia seguinte à reeleição, a Folha, também nesse ponto, deixou explícito o tom de suas preocupações enquanto ator político de oposição ao governo. Uma das chamadas para textos opinativos destaca que a "Petista terá dificuldade em nomear uma equipe econômica com credibilidade". Cabe ressaltar que os próprios jornais alertam que as opiniões dos articulistas, expressas em suas páginas, não necessariamente refletem a opinião do veículo. Seria ingênuo imaginar, porém, que isso é um compromisso com a objetividade e com a imparcialidade. A Folha, mais que O Globo, traz comumente opiniões antagônicas em suas páginas dedicadas ao debate entre articulistas, eventualmente até imprimindo na capa as chamadas que destoam do tom geral de sua cobertura negativamente orientada em relação ao governo Dilma, mas a análise da narrativa do jornal durante a crise demonstra que essa atitude é incidental, não estrutural. Em outras palavras, é uma espécie de prestação de contas com a opinião contrária, não um debate autêntico entre posições antagônicas dentro de uma narrativa negativa.

Antes de partimos para a análise da narrativa, é importante destacarmos aspectos quantitativos que ajudam a compreender a intriga contada nas páginas dos dois jornais em 19 meses de cobertura. A partir de levantamento feito pelo Manchetômetro², o gráfico a seguir mostra-nos que Dilma já enfrentou o fogo pesado da mídia logo depois da reeleição. $O$ jornalismo adversário começa imediatamente após o resultado das urnas - visto de outro ângulo, ele continua exatamente de onde estava até o dia da eleição e intensifica-se após o início oficial do segundo mandato, em janeiro de 2015.

\section{A intriga e os narradores}

As teorias do jornalismo nos ensinam que o conflito é um valor-notícia a ser observado pelos jornalistas ao selecionarem os fatos que irão se transformar em notícia (TRAQUINA, 2004; SCHUDSON, 1978; TUCHMAN, 1983). Motta e Guazina (2010, p. 133) colocam-no em um nível hierárquico superior, ao sustentar

2 No site do Manchetômetro é possível produzir, a partir da enorme base de dados disponibilizada, gráficos personalizados de cobertura por tema, personagem, jornal e período de cobertura. 0 site é o www.manchetometro. com.br 
que o conflito é o elemento estruturante do jornalismo político:

0 conflito é uma categoria dramática que centraliza a narrativa jornalística e tece os fios que encadeiam as ações das personagens da política. Posicionando as personagens umas contra as outras na narrativa jornalística, o conflito estabelece os episódios que projetam sequências lógico-temporais e concatenam enredos de histórias virtuais mais ou menos completas, embora o foco recaia sobre os personagens que assumem a proeminência nos episódios.

O nosso corpus, formado por 359 manchetes e chamadas de capa da Folha de S. Paulo e 434 de O Globo, é pleno de exemplos nos quais a narrativa do fato estrutura-se na ideia básica do conflito, seja político, seja econômico, entre os atores sociais relevantes para os jornais e o governo federal. Na análise de narrativa, a intriga e o conflito não são sinônimos. Conflito é valor-notícia; intriga é o enredo sob o qual se constrói uma história.

Qual é a intriga que os jornais contam entre 27 de outubro de 2014 e 12 de maio de 2016 ? É a transformação de um governo recém-reeleito em inviável e prejudicial ao país. Conforme dito anteriormente, a cobertura negativa intensificou-se imediatamente após o resultado das urnas, e é possível identificar

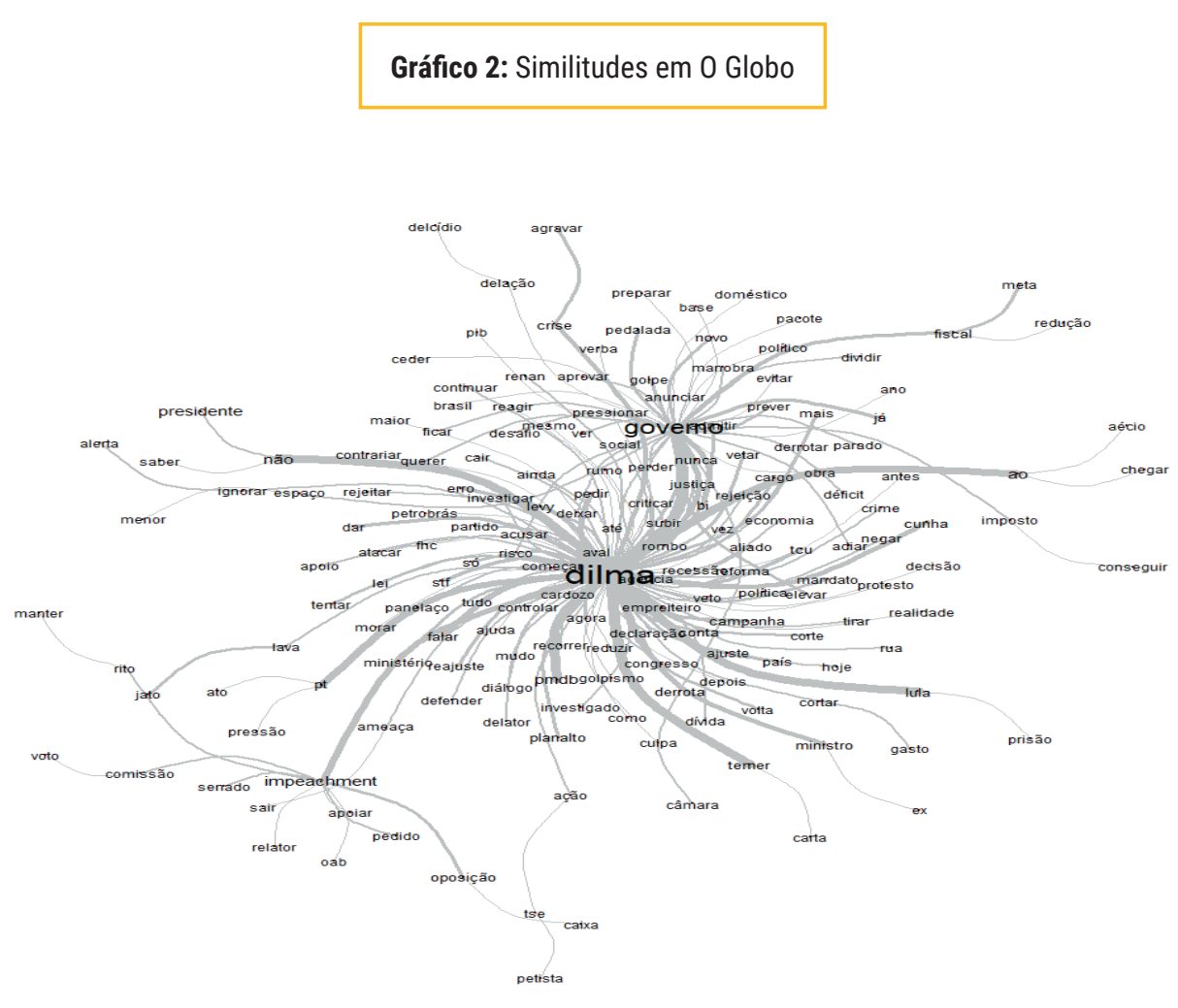

Fonte: elaboração da autora a partir de dados processados no Iramuteq 
na reeleição o evento perturbador que levou os jornais, como atores políticos de oposição, a iniciarem uma narrativa - a princípio velada, depois explícita - de inviabilidade de seguir com Dilma até 2018. Essa inviabilidade política era manifesta nos dois jornais estudados, mas as nuances não são iguais para os dois veículos.

O Globo teceu uma intriga eminentemente política, enquanto a Folha de S. Paulo teceu uma intriga com aspectos econômicos dominantes sobre os políticos. Em O Globo, 82,95\% das notícias publicadas na capa eram sobre o tema Política e seus personagens, enquanto, na Folha, esse número foi de 64,19\%. Na Folha, $45,4 \%$ das notícias sobre economia foram dadas como manchete; em O Globo, $36,5 \%$ das notícias de economia foram manchete. $\mathrm{Na}$ codificação utilizada nesta pesquisa, Política eram as notícias que se referiam aos termos Dilma, Lula, FHC, Michel Temer, Aécio Neves, Eduardo Cunha, Governo, Oposição, PT, PMDB e PSDB. Já Economia eram notícias que se referiam aos termos Mercado, Fiesp, Imposto, Empresários, Bolsa, Dólar, Preços e Câmbio.

Outra nuance que diferenciou os dois jornais é que, na amostra, a Folha usou mais vezes a manchete para noticiar a crise do segundo

Gráfico 3: Similitudes da Folha de S. Paulo

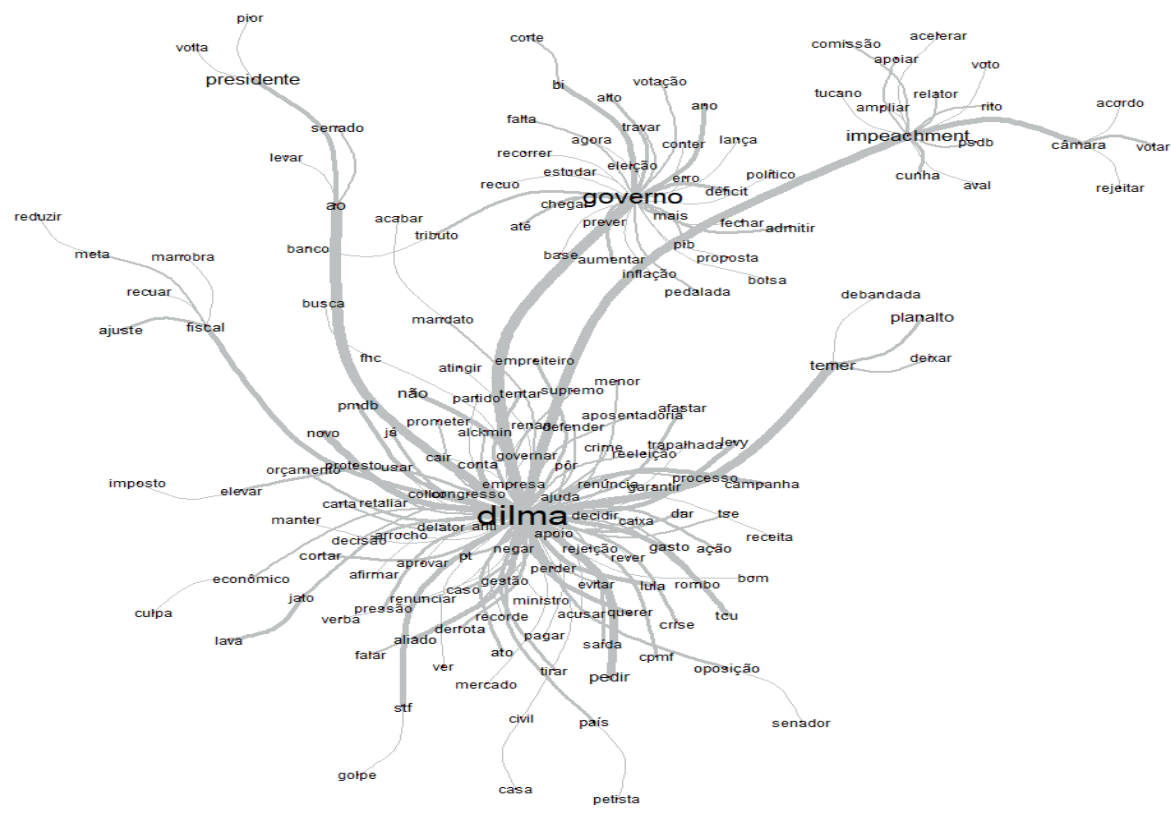


mandato de Dilma que O Globo: $38,11 \%$ das 359 notícias sobre os problemas políticos e econômicos do mandato foram manchete no jornal paulista, enquanto que em O Globo apenas $28,34 \%$ dos 434 textos analisados são manchetes. Manchetes referem-se à notícia principal da edição, enquanto chamadas são os títulos das demais notícias com destaque na capa.

O gráfico de similitude ${ }^{3}$ apresentado a seguir permite-nos visualizar a relação entre as palavras que o jornal utiliza em seus títulos, o que nos ajuda a compreender o caráter político da crise narrada nas páginas de O Globo. No centro da intriga, estão Dilma e a incapacidade política de conduzir o país dividido. O gráfico mostra as palavras mais associadas a Dilma (agente político individual; portanto, protagonista da intriga como problema político) e a Governo (agente político coletivo, coadjuvante da intriga). A personalização da crise política fica muito clara a partir da análise de similitude entre os termos utilizados nas manchetes e as chamadas publicadas pelo jornal: se a crise é política, e se o protagonista é identificável, o desfecho da narrativa aparece sob a forma de impeachment, formando um terceiro núcleo de argumentação dentro do drama narrado.
Agora, vejamos o caso da Folha de S. Paulo. O gráfico de similitude também mostra que a crise narrada era política, mas as palavras associadas a Dilma também trazem o aspecto econômico privilegiado pelo jornal na construção da intriga estruturante de sua narrativa. O vocabulário da Folha de S. Paulo é mais econômico que político, apesar da natureza política da crise. Isso nos permite sustentar a hipótese de que a intriga estruturante na narrativa desse jornal é a crise econômica, cujo desfecho é o mesmo sustentado pela narrativa de O Globo: o impeachment, visto que protagonista (Dilma) e coadjuvante (Governo) aglomeram as mesmas ideias sintetizadas nas manchetes e chamadas de capa.

\section{Os personagens}

Construir uma narrativa pressupõe uma intriga, um narrador e os personagens. Dilma, sem dúvida, é o personagem protagonista da história contada pelos jornais enquanto agente individual, e Governo é o personagem protagonista enquanto agente coletivo. Nas manchetes e chamadas de capa em análise, Dilma é alguém que se defende. É uma protagonista passiva, que apenas reage às situações que são postas diante dela. Segundo a narrativa lida nas manchetes e chamadas 
de capa, é uma personagem que reage mal, tardia e desastradamente aos fatos. A construção, portanto, é de uma protagonista fraca, sem pulso, fadada ao fracasso. O governo, por extensão, tem as mesmas características.

As palavras mais associadas à presidente Dilma e seu governo nas manchetes e chamadas das amostras de ambos os jornais são categóricas: derrota (10 vezes tanto em O Globo quanto na Folha), admitir (9 vezes em cada jornal), tentar (9 vezes em O Globo), rombo (9 vezes em O Globo e 5 na Folha), gasto e déficit (8 vezes na Folha, 4 em O Globo), perder ( 7 vezes na Folha, 5 em O Globo), pressão ( 6 vezes na Folha, 4 em O Globo), negar (6 vezes na Folha, 5 em O Globo), erro (6 vezes na Folha, 10 vezes em O Globo), defender (6 vezes na Folha, 4 em O Globo), trapalhada (3 vezes na Folha; não aparece em O Globo). São palavras que conotam negatividade. Toda vez que os jornais usaram o verbo admitir na amostra, por exemplo, a notícia dizia respeito a situações em que a presidente precisou corroborar a narrativa feita pelos jornais sobre seu governo, ou seja, ela sempre "admitia" os dados negativos referentes à economia ou à sua situação política.

Nas manchetes sobre o relacionamento de Dilma com o Congresso, a narrativa tinha como protagonista uma presidente constantemente derrotada pela casa ("Câmara impõe primeira derrota a Dilma após reeleição"| "Presidente do Senado promete nova derrota a Dilma"| "Câmara elege Cunha e derrota Dilma"| "No plenário, Cunha já derrota governo"/ "Derrota tira poder de Dilma para indicações no STF"| "Dilma é derrotada e deve vetar reajuste"| "Depois de série de derrotas, Dilma aposta na judicialização da disputa política", por exemplo).

Os demais personagens da narrativa são antagonistas: Michel Temer, PMDB, PSDB, Congresso, Eduardo Cunha. São personagens que aparecem de forma ativa - e não reativa, como Dilma/Governo. Isso nos diz muito sobre a estrutura da história contada pelos jornais. Na amostra de manchetes e chamadas selecionadas, PMBD aparece em 26 títulos de O Globo e em 11 da Folha. Oposição, associada a dados negativos para Dilma, aparece 11 vezes na capa de ambos os jornais. Temer é o personagem de manchetes e chamadas 21 vezes na amostra de O Globo, 22 na Folha. Cunha é o protagonista 8 vezes na Folha e 19 em O Globo - dado que corrobora a narrativa de crise política acima da econômica no jornal carioca. Já o PSDB virtualmente sumiu da narrativa da capa devidamente nomeado (aparece como Oposição, mas oposição é um ente menos definido, já que é um agregado de várias siglas): 2 vezes é o protagonista das chamadas de O Globo e 4 na Folha. Congresso é o sujeito de 8 chamadas de O Globo e 7 na Folha. 


\section{A narrativa}

A narrativa que começa com a reeleição de Dilma e termina (em nosso recorte) com seu afastamento pelo Senado é uniforme: a intriga é posta em termos claros pelos jornais, os personagens têm suas motivações identificadas, sabemos quem é o protagonista e quem são seus antagonistas, conhecemos os narradores. A intriga parece simples: incapacidade de Dilma comandar o país até 2018. A simplicidade, porém, é aparente: o contexto de narração dessa intriga é complexo e remete não apenas ao resultado da eleição, contrário à expectativa de que a presidente poderia ser derrotada, mas também ao contexto geral da política brasileira contemporânea. Se Dilma não pôde ser derrotada nas urnas, a narrativa jornalística mostrou que a presidente poderia ser derrotada em pleno governo. Essa narrativa ecoa o discurso do candidato de oposição derrotado nas urnas, Aécio Neves, dos empresários reunidos em torno da Federação das Indústrias do Estado de São Paulo (FIESP) e dos parlamentares que elegeram Eduardo Cunha para a presidência da Câmara, ele mesmo opositor da presidente reeleita.

Os jornais publicam, de forma crescente, notícias negativas sobre o governo e a governante.
De acordo com a sociologia do jornalismo e a classificação de Gaye Tuchman (1983), a crise política que culminou no afastamento de Dilma é uma notícia em desenvolvimento: há um início bem marcado (a reeleição), há a sinalização do desfecho ideal para os narradores (o impeachment), e há o final da narrativa (que esta pesquisa não contempla - o impeachment propriamente dito) ${ }^{4}$. Há uma unidade inteligível.

A narrativa na capa de O Globo é mais valorativa que informativa, na medida em que o jornal dá amplo espaço para chamadas de textos opinativos, que estão no miolo. Nas manchetes e chamadas de O Globo, foram contabilizados 90 adjetivos e, na Folha, 96. Neste jornal, a maior parte dos adjetivos referia-se ao linguajar da cobertura econômica. Em O Globo, os adjetivos estavam mais ligados à avaliação da personagem Dilma.

A partir de janeiro de 2015 críticas em forma de manchetes negativas citando nominalmente Dilma começam a aparecer com mais frequência na capa dos jornais. A personagem é errática ("Presidente recua do recuo e volta a defender superávit", FSP, 9/04/15); despreparada para o jogo 
da política ("Dilma terá embate duro e não parece estar politicamente equipada para enfrentá-lo", O Globo, 31/12/14); medíocre ("Ao definir o ministério, Dilma mostra a mesma mediocridade que marcou o seu governo", O Globo, 01/01/15); sem prestígio ("Temer diz que é difícil Dilma resistir com baixo prestígio", FSP, 04/09/15); fraca ("Base se nega a dar apoio a pacote fiscal e Dilma recua", FSP, 16/09/15); culpada ("Erros do primeiro mandato de Dilma levam país à recessão", O Globo, 10/02/15); impopular ("Na TV Dilma defende ajuste, nas ruas panelaço", O Globo, 09/03/15; "Fala de Dilma gera panelaço em 12 capitais", FSP, 09/03/15). Até o afastamento, em 12 de maio de 2016, o tom das críticas à personagem intensifica-se, e a narrativa converge para a ideia de que o Brasil ficará melhor sem Dilma.

Outros aspectos chamam a atenção na narrativa dos jornais. As chamadas para textos opinativos nas capas de ambos os diários cumprem papéis distintos: em O Globo, elas reforçam a narrativa de apoio ao impeachment por parte do veículo; na Folha, elas tentam construir a imagem de que o jornal é equilibrado em sua cobertura, dando voz a opiniões divergentes da narrativa construída.

Conforme discutimos na parte teórica, a notícia é uma construção cultural, econômica e política - técnica somente ela não é, pois dizer que a notícia é um texto técnico assumiria que a objetividade e a imparcialidade jornalísticas existem. Em nossa amostra de manchetes e chamadas de capa, encontramos textos construídos de acordo com o figurino padrão da técnica jornalística: quem fez o quê-onde-como-por quê-com que consequências. Mas a técnica de construção do lead não deixa o texto imune à subjetividade e à parcialidade, uma vez que a notícia tem uma agência e uma agenda. A agência é maior que o narrador no caso, os jornais.

Os jornais são empresas cujo objetivo não é apenas o lucro econômico: jornais são, historicamente, porta-vozes de interesses de grupos econômicos, políticos e culturais. Não são, portanto, devotos da notícia como entidade ensimesmada. A agenda é tributária dos interesses dos atores que se agregam e dialogam através das páginas impressas: o afastamento da presidente eleita e sua substituição por alguém que pudesse colocar em andamento o plano de governo derrotado nas urnas. A agenda foi cumprida, e os jornais, sem dúvida, contribuíram para a naturalização do discurso de que a presidente eleita não seria viável para permanecer à frente da República até a próxima eleição.

\section{Considerações finais}

O jornalismo adversário cumpre um papel importante na desestabilização de governos, 
mas não é capaz, sozinho, de manipular a opinião pública a ponto de determinar a sorte dos demais agentes do processo político, visto que existe uma série de fatores que concorrem para uma crise chegar a um desfecho ou outro. Afinal, basta olhar para as notícias negativas durante o governo Temer (agosto de 2016 a $1^{\circ}$ de janeiro de 2019), que se manteve, apesar delas, e conseguiu fazer avançar parte de sua agenda em detrimento da opinião pública. Apesar dessa ressalva, os eventos noticiados durante a crise do governo Dilma foram espetacularizados e amplificados por uma imprensa que agiu como adversária do governo e da governante, ecoando os discursos e as narrativas dos grupos interessados no impeachment.

Os deputados e senadores que votaram contra a presidente tinham interesses pessoais e econômicos bem delimitados e encontraram, na cobertura jornalística, espaço para mostrarem aos seus eleitores seu alinhamento com uma causa "popular" para aproximadamente metade do eleitorado. Lembremos que a diferença entre Dilma e o segundo colocado nas eleições, Aécio Neves, não foi avassaladora, e o país que saiu das urnas em outubro de 2014 já estava dividido. A imprensa ficou do lado dos derrotados, ampliou suas vozes e silenciou ou reduziu o espaço de visibilidade das opiniões dos defensores da presidente. Junte-se a esse cenário a atuação do judiciário, que levou (e ainda leva) a cabo uma operação contra a corrupção que atinge maciçamente apenas um dos lados do espectro político.

A imprensa brasileira não criou a crise política (ou econômica), mas a intensificou por meio de sua narrativa centralizada na incapacidade política da presidente eleita em debelar a crise econômica. Nas manchetes e chamadas de capa analisadas, os jornais não deram ênfase às acusações de fraude fiscal que teria sido cometida por Dilma Rousseff, as chamadas "pedaladas fiscais". A ênfase foi na imperícia da governante e em sua incapacidade de negociar a solução para a crise política do país com o Congresso Nacional. Concluímos que Dilma Rousseff perdeu a disputa pela narrativa de seu governo, e isso foi um dos fatores para a derrota política que culminou com seu impeachment.

\section{Referências}

ALDÉ, Alessandra, MENDES, Gabriel, FIGUEIREDO, Marcus. Tomando Partido: Imprensa e política nas eleições de 2006. Política SSociedade, v. 10, p. 20-28, 2007.

ALSINA, Miguel Rodrigo. La Construción de la Noticia. Barcelona: Paidós, 1996.

BIRD, Elizabeth, DARDENNE, Robert. Rethinking News and Myth as Storytelling. In: WAHL-JORGENSEN, Karin, HANITZSCH, Thomas. The Handbook of Journalism Studies. 
New York and London: Routledge, 2009, pp.205-2017.

COOK, Timothy. Governing with the News: the News media as a political institution. zed. Chicago: Chicago Press, 2005.

\section{FAIRCLOUGH, Norman. Media Discourse.}

New York: St Martin's Press, 1995.

FERES JÚNIOR, João. BARBABELA, Eduardo, MIGUEL, Lorena. SASSARA, Luna. Testando a hipótese do contrapoder: a cobertura das eleições de 1998 a 2014. Anais do VI Congresso da Associação Brasileira de Pesquisadores em Comunicação e Política (Compolítica). Rio de Janeiro, de 22 a 25 de abril de 2015.

GRABER, Doris A.; MACQUAIL, Denis; NORRIS, Pippa. The Politics of the news, The news of the Politics. 2ed. Washington: CQ Press, 2008

GUAZINA, Liziane Soares. Jornalismo em Busca da Credibilidade: A cobertura adversária do Jornal Nacional no Escândalo do Mensalão. 256 F. Tese (Doutorado em Comunicação Social) - Faculdade de Comunicação, UNB, Brasília, 2011.

LATTMAN-WELTMAN, Fernando, CARNEIRO, José Alan Dias, RAMOS, Plínio de Abreu. A imprensa faz e desfaz um presidente: o papel da imprensa na ascensão e queda do "fenômeno" Collor. Rio de Janeiro: Nova Fronteira, 1994.

LATTMAN-WELTMAN, Fernando, CHAGAS, Viktor. Mercado Futuro: a economia política da (re)partidarização da imprensa no Brasil. In: Dados - Revista de Ciências Sociais. Rio de Janeiro, vol. 59, n. 2, pp. 323-354, 2016.
LIMA, Venício. Mídia, crise política e poder no Brasil. São Paulo: Fundação Perseu Abramo, 2006.

MATOS, Carolina. Jornalismo e política no Brasil contemporâneo. São Paulo: Publifolha, 2008.

MIGUEL, Luís Felipe. Política e Mídia no

Brasil: episódios da história recente. Brasília: Plano, 2002.

MOTTA, Luiz Gonzaga. Análise Crítica da Narrativa. Brasília: Editora UNB, 2013.

MOTTA, Luiz Gonzaga; GUAZINA, Liziane. $O$ conflito como categoria estruturante da narrativa jornalística: o caso do Jornal Nacional. Brazilian Journalism Research, v.6, n.1, 2010.

NORRIS, Pippa, NAI, Alessandro (org). Election Watchdogs: Transparency, accountability and Integrity. New York: Oxford University Press, 2017. Cap.10

NORRIS, Pippa (org). Public Sentinel: News media \& Governance Reform. The World Bank Publications: Washington, 2009.

NORRIS, Pippa, ODUGBEMI, Sina. Assessing the Extent to Which the News Media Act as Watchdogs, Agenda Setters, and Gatekeepers. In: Public Sentinel: News media \& Governance Reform. The World Bank Publications:

Washington, 2010.

SCHUDSON, Michael. Discovering the News: a social history of American newspapers. New York: Basic Books Inc., 1978.

SOUSA, Jorge Pedro. Teorias da Notícia e do Jornalismo. Chapecó: Argos, 2002.

SPARROW, Bartholomew H. Uncertain

Guardians: the News media as a political 
institution. Baltimore: The Johns Hopkins

University Press, 1999.

THOMPSON, John. Brookshire. 0 escândalo

político: poder e visibilidade na era da

mídia. Petrópolis: Vozes, 2002.

TRAQUINA, Nelson (org). Teorias do

Jornalismo: porque as notícias são como são.

vol. 1. Florianópolis: Insular, 2004.

TUCHMAN, Gaye. La Producción de la

Noticia: estudio sobre la construcción de la

realidad. Barcelona: Gili, 1983.

VAN DIJK, Teun. La noticia como discurso.

Barcelona: Paidós, 1996.

WAISBORD, Silvio. Watchdog Journalism

in South America: news, accountability, and democracy. New York: Columbia University Press, 2000. 


\section{Adversarial journalism: the crisis of Dilma Rousseff's second term on the front page}

\section{Abstract}

The article analyses the narrative of adversarial journalism in the headlines and calls cover of the newspapers O Globo and Folha de S. Paulo during the crisis of the second mandate of the president Dilma Rousseff. We worked with the concept of adversarial journalism and the notion of the press as a political party to explain the role of newspapers in the crisis that culminated in the impeachment of the president-elect. We used the critical analysis of the narrative to analyse the 793 textual units that make up the corpus of the research. The results show that newspapers behaved like political contenders and were active agents in the process of destabilizing the government during the crisis.

\section{Keywords}

Adversarial Journalism. Narrative. Dilma Rousseff.

\section{Periodismo adversario: la crisis} del segundo mandato de Rousseff en la portada del diário

\section{Resumen}

El artículo analiza la narrativa del periodismo adversario en los titulares y llamadas de portada de los diarios O Globo y Folha de São Paulo durante la crisis del segundo mandato de la presidenta Rousseff. Trabajamos con el concepto de periodismo adversario y con la noción de prensa como partido político para explicar el papel de los periódicos en la crisis que culminó con el impeachment de la presidenta electa. Utilizamos el análisis crítico de la narrativa para analizar las 793 unidades textuales que componen el corpus de la investigación. Los resultados muestran que los periódicos se comportaron como contendientes políticos y fueron agentes activos en el proceso de desestabilización del gobierno durante la crisis.

\section{Palabras-clave}

Periodismo Adversario. Narrativa. Dilma Rousseff.

\section{Li-Chang Shuen}

Doutora em Ciências Sociais pelo Centro de Pesquisa e Pós-Graduação sobre as Américas da Universidade de Brasília. Professora Adjunta do Departamento de Comunicação Social da Universidade Federal do Maranhão - São Luís, Maranhão, Brasil. E-mail: lichangshuen@gmail.com 